\title{
National Ignition Facility SubSystem Design Requirements \\ Target Diagnostics Subsystem \\ SSDR 1.8.3
}

D. Lee

October 28, 1996

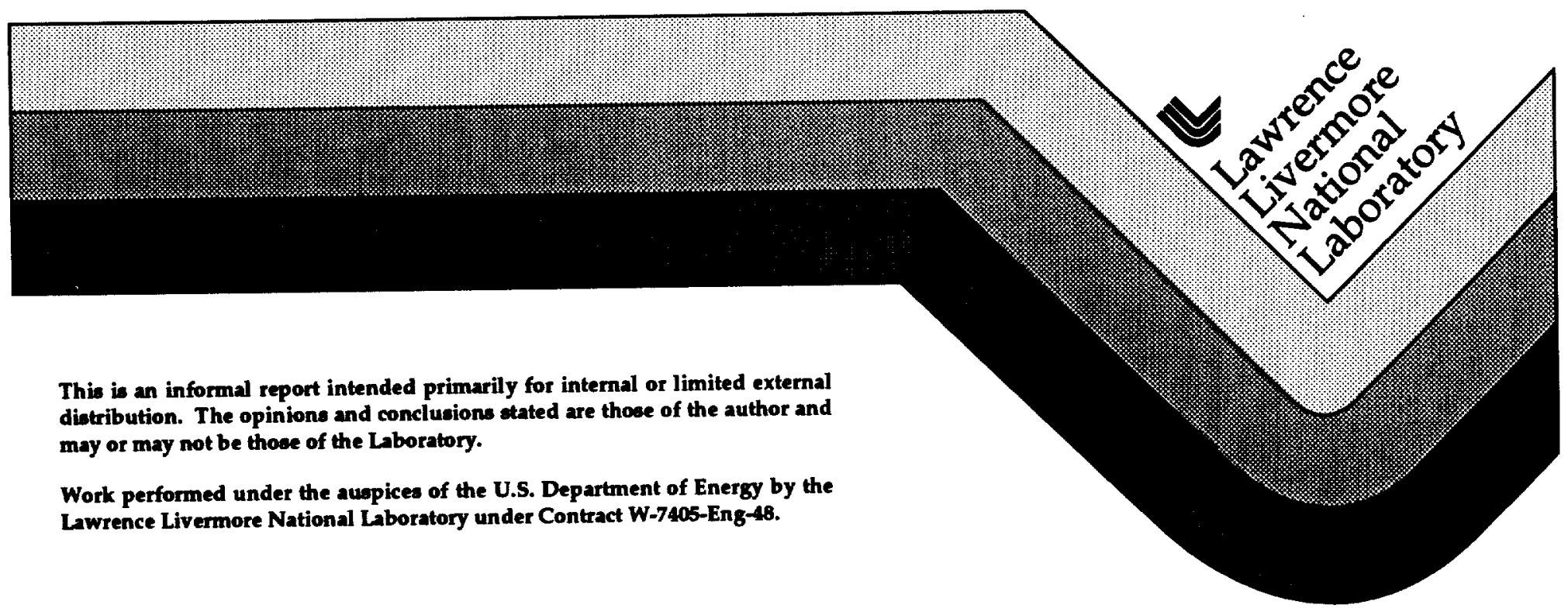




\section{DISCLAMMER}

This document was prepared as an account of work sponsored by an agency of the United States Covernment. Neither the United States Government nor the University of California nor any of their employees, makes any warranty, express or implied, or assumes any legal liability or responsibility for the accuracy, completeness, or usefulness of any information, apparatus, product, or process disclosed, or represents that its use would not infringe privately owned rights. Reference herein to any specific commercial product, process, or service by trade name, trademark, manufacturer, or otherwise, does not necessarily constitute or imply its endorsement, recommendation, or favoring by the United States Covernment or the University of California. The views and opinions of authors expressed herein do not necessarily state or reflect those of the United States Government or the University of Califorria, and shall not be used for advertising or product endorsement purposes.

This report has been reproduced directly from the best available copy.

Available to DOE and DOE contractors from the Office of Scientific and Technical Information

P.O. Box 62, Oak Ridge, TN 37831

Prices available from (615) 576-8401, FTS 626-8401

Available to the public from the National Technical Information Service

U.S. Department of Commence 5285 Port Royal Rd.

Springfield, VA 22161 


\title{
National Ignition Facility
}

\section{Subsystem Design Requirements}

\author{
Target Diagnostics Subsystem \\ SSDR 1.8.3 \\ Revision B \\ 28 October, 1996
}

Prepared by:

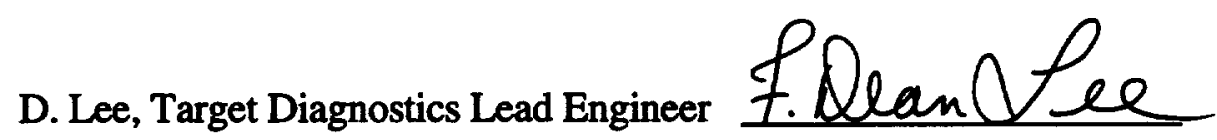

Date $10 / 24 / 96$

Reviewed:

V. Karpenko, Target Experimental System Engineer

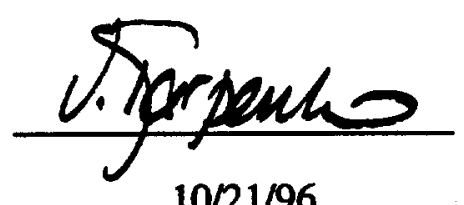

Date

$10 / 21 / 96$

R. Sawicki, NIF Special Equipment APE

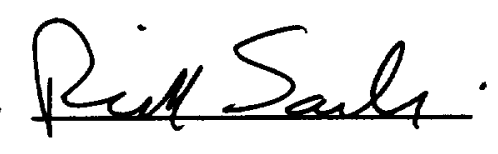

Date

$10 / 18 / 96$

Level 4 Configuration Control Board Approval:

S. Kumpan, NIF Project Engineer

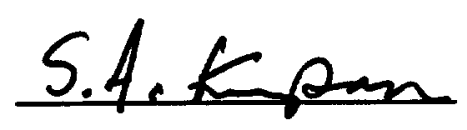

Approval Date

$10 / 28 / 96$ 


\section{Table of Contents}

\begin{tabular}{|c|c|}
\hline $\begin{array}{l}\text { Paragraph } \\
1.0 \\
2.0 \\
2.1 \\
2.2 \\
2.3 \\
2.4 \\
2.5 \\
2.6 \\
3.0 \\
3.1 \\
3.1 .1 \\
3.1 .1 .2 \\
3.1 .2 \\
3.1 .3 \\
3.1 .3 .1 \\
3.1 .3 .2 \\
3.1 .4 \\
3.1 .5 \\
3.2 \\
3.2 .01 \\
3.2 .02 \\
3.2 .03 \\
3.2 .03 .1 \\
3.2 .03 .2 \\
3.2 .03 .2 .1 \\
3.2 .03 .2 .2 \\
3.2 .03 .2 .3 \\
3.2 .03 .2 .4 \\
3.2 .04 \\
3.2 .04 .1 \\
3.2 .04 .1 .1 \\
3.2 .04 .1 .1 .2 \\
3.2 .04 .1 .1 .3 \\
3.2 .04 .1 .1 .4 \\
3.2 .04 .1 .1 .5 \\
3.2 .04 .1 .1 .6 \\
3.2 .04 .2 \\
3.2 .04 .2 .1 \\
3.2 .04 .3 \\
3.2 .05 \\
3.2 .05 .1 \\
3.2 .05 .1 .1 \\
3.2 .05 .1 .2 \\
3.2 .05 .2 \\
3.2 .05 .2 .1 \\
3.2 .05 .2 .2 \\
3.2 .05 .3 \\
3.2 .05 .3 .1 \\
3.2 .05 .3 .2 \\
\end{array}$ & $\begin{array}{l}\text { Title } \\
\text { Scope } \\
\text { Applicable Documents } \\
\text { Applicable NIF Project Documents } \\
\text { Applicable US Government Orders, Codes, and Standards } \\
\text { Applicable National Consensus Codes and Standards } \\
\text { Applicable LLNL Standards } \\
\text { Supporting Documentation Standards } \\
\text { References } \\
\text { Requirements and Verification } \\
\text { System Definition } \\
\text { System Description } \\
\text { Target Diagnostic Data Acquisition System } \\
\text { System Functions } \\
\text { System Diagrams } \\
\text { System Operating Modes } \\
\text { Dry Run Operating Modes } \\
\text { System Interfaces } \\
\text { Major Subsystems } \\
\text { System Characteristics and Verification } \\
\text { Laser system performance and verification diagnostics } \\
\text { Ignition and Weapons Physics Experimental Diagnostics } \\
\text { Diagnostic Instrument Manipulator (DIM) } \\
\text { Performance Characterisitcs } \\
\text { Physical characteristics } \\
\text { General (size, configuration, etc.) } \\
\text { Material (contamination, vacuum, activation) } \\
\text { Electrical (wiring, shielding, fiber optics, controls, etc.) } \\
\text { Mechanical (stability, deflection, load) } \\
\text { Target Area Data Acquisition System } \\
\text { Unclassified Data Acquisition System } \\
\text { Performance Characteristics } \\
\text { Computer/Software System Performance Requirements } \\
\text { Efficiency of Operation } \\
\text { Throughput Time Requirements } \\
\text { Data Storage and Transfer Requirements } \\
\text { Terms and Test Methods } \\
\text { Classified Data Acquisition System } \\
\text { Performance Characteristics } \\
\text { Other Diagnostic Systems } \\
\text { Target Area Timing/Trigger and Fiducial System } \\
\text { Fast Timing Signals } \\
\text { Performance Characteristics } \\
\text { Physical Characteristics } \\
\text { Precision Timing Signals } \\
\text { Performance Characteristics } \\
\text { Physical Characteristics } \\
\text { Fiducal Optical and Electrical Signals } \\
\text { Performance Characteristics } \\
\text { Physical Characteristics }\end{array}$ \\
\hline
\end{tabular}




\section{Table of Contents}

Paragraph

3.2 .06

3.2.06.1

3.2.06.2

3.2 .07

3.2 .08

3.2.08.1

3.2.08.2

3.2 .09

3.2.09.1

3.2.09.2

3.2 .10

3.2.10.1

3.2.10.2

3.2.10.3

3.2.10.4

3.2 .10 .5

3.2 .10 .6

3.2 .11

3.2.11.1

3.2.11.2

3.2.11.3

3.3

3.4

3.4 .1

3.4 .2

4.0

4.1
Title

Central Diagnostic Vacuum System

Performance Characteristics

Physical Characteristics

EMI Protection, Grounding and Shielding, and Radiation Susceptability

Unclassified Control Room

Performance Characteristics

Physical Characteristics

Classified Control Room

Performance Characteristics

Physical Characteristics

Reliability, Availability, Maintainability

Lifetime

Replaceability

Inherent Availability

Reliability

Maintainability

Recovery from Abnormal Events

Environmental

Ambient Temperature, Humidity, and Pressure

Vibration Enviroment

EMI, EMP, and Radiation

Design and Construction

Logistics

Spares

Maintenance

QA Provisions

Q-level Assigned 


\subsection{Scope}

This SSDR establishes the performance, design, development, and test requirements for the Target Experimental System's Diagnostic System, WBS 1.8.3. This includes the individual diagnostic components, the Target Diagnostic Data Acquisition System (Target DAS), the diagnostic vacuum system, the timing/fiducial system, and the EMI protection system.

\subsection{Applicable Documents}

2.1 Applicable NIF Project Documents

National Ignition Facility Functional Requirements and Primary Criteria, Revision 1.4, L-15983-3, February, 1996

National Ignition Facility System Design Requirement 003, Target Experimental System Design Requirements, Revision A, NIF-96-227, L-21706-01

NIF-LLNL-93-044/L-15958-1, National Ignition Facility Quality Assurance Program Plan, November 1993

NIF Environmental, Safety, and Health Management Plan, November 1995, NIF-LLNL-95-599, L-20523-1

"Proposed Metrication Policy for NIF," memo from R. Sawicki, NIF-LLNL-96-038, L-21248-01, 21 January, 1996

NIF Grounding Plan, NIF-LLNL-94-211, L-17346-1.

2.2 Applicable US Government Orders, Codes, and Standards

US. Government DOE General Orders:

DOE Order 1330.1D, Computer Software Management

DOE Order 1360.1B, Acquisition and Management of Computing Resources

DOE 4700.1-Project Management System

DOE 5480.1B-Environmental Protection, Safety, and Health Protection Program for DOE Operations

DOE 5480.4-DOE Environmental Protection, Safety, and Health Protection Standards

DOE 5480.9-Construction Safety and Health Program

DOE 5480.10-Contractor Industrial Hygiene Program

DOE 5481.1B - Safety Analysis and Review System (for non-nuclear facilities and hazards only)

DOE 5500.2B-Emergency Categories Classes and Notification and Reporting Requirements

DOE 5500.3A-Planning and Preparedness for Operational Emergencies

DOE 5632.5-Physical Protection of Classified Matter

DOE 5700.6C-Quality Assurance

DOE Order 6430.1A - General Design Criteria

US. Government DOE Orders relating to Safeguards and Security:

DOE Order 1360.2B, Unclassified Computer Security Program

DOE Order 5300.4C, Telecommunications: Protected Distribution Systems

DOE Order 5639.6, Classified Computer Security

Program

\subsection{Applicable National Consensus Codes and Standards}

General Standards:

29 CFR 1910.7 Definitions and Requirements for a Nationally Recognized Testing Laboratory (NRTL)

NEPA (National Environmental Policy Act) 42USC 4321 et seq.

Safety Standards:

National Fire Protection Association (NFPA)-70 National Electrical Code 
ANSI C2-1990, National Electric Safety Code

American National Standard for Safe Use of Lasers

RG-1.105 Instrumentation setpoints for Safety Related Systems

RG-1.152 Criteria for PLC software for safety related systems

RG-1.153 Criteria for power, instrumentation and control portions of safety systems.

IEC-55-0812 Analysis Techniques for System Reliability Procedure to Failure Modes and Effects Analysis

NEMA ICS6 Enclosures for Industrial Control Systems,UL Standards, Underwriters Laboratory, Inc.

California Health Safety Code

29 CFR 1910 Occupational Safety and Health Act (OSHA)

Software and Electronic Standards:

Ethernet IEEE-802.3 Local Area Network for Data Communications

FDDI Fiber Distributed Data Interface, ANSI Standard X3.139-1987

RS-232C EIA Serial interface standard

RS-485 EIA Multi-drop serial interface standard

IEEE-488 Standard Digital Interface for Programmable Instrumentation, ANSI/IEEE Std 488.1-1987 and

ANSI/IEEE Std 488.2-1987

VMEbus IEEE-1014

RS-170 EIA Video interface standard

Ada 8.3 ANSI/MIL-STD-1815A-1983, programming language

Ada 95 International Standard ANSI/ISO/IEC-8652:1995, January 1995

X11 X Window System, Version 11, windows graphics standard, MIT X Consortium

OSF/Motif Motif graphical user interface, Open Systems Foundation

Postscript Text and graphics printing language, Adobe Systems Inc.

POSIX IEEE-1003 portable application programming environment

TCP/IP Protocol stack for network communications

OSI/ISO Open Systems Interconnect protocol stack for network communications

OSF/DCE Distributed Computing Environment, Open Systems Foundation

OSF/DME Distributed Management Environment, Open Systems Foundation

\subsection{Applicable LLNL Standards General:}

LLNL Committee on Metrification, 10 October 1992, "LLNL Metric Transition Path"

LLNL M-012 Rev 7, Feb 1993, "Design Safety Standards -Mechanical Engineering"

LLNL M-010, March 1989, "Health and Safety Manual"

LLNL, "Hazards Control Manual"

LLNL, M-256 "Mechanical Engineering Design Practice"

LLNL "Mechanical Engineering Policy Procedures Manual"

LLNL "Electronics Engineering Standard Documentation, Engineering and Design Quality, and Configuration Management “ LED 43-20-01-A10

LLNL "EE Design \& Drafting Manual"

\subsection{Supporting Documentation Standards}

Instrument Society of America, ISA-S5.1, Instrumentation Symbols and Identification

Instrument Society of America, ISA-S5.2, Binary Logic Diagrams for Process Operations

Instrument Society of America, ISA-S5.3, Graphics Symbols for Distributed Control/Shared Display

Instrumentation, Logic and Computer Systems

Instrument Society of America, ISA-S5.4, Instrument Loop Diagrams

Instrument Society of America, ISA-S5.5, Graphics Symbols for Process Displays

ANSIIIEEE Std 730.1-1989, IEEE Standard for Software Quality Assurance Plans

Software Guidelines Standards, Practices, and Conventions (Final DRAFT), Applications Development

Department, Lawrence Livermore National Laboratory, August 10, 1992

ANSI/IEEE Std 830-1984, IEEE Guide for Software Requirements Specification 
ANSI/IEEE Std 1016-1987, IEEE Recommended Practice for Software Design Descriptions ANSI/IEEE Std 828-1983, IEEE Standard for Software Configuration Management Plans ANSI/IEEE Std 982.1-1988, IEEE Standard Dictionary for Measures to Produce Reliable Software ANSI/IEEE Std 982.2-1988, IEEE Guide for the Use of IEEE Standard Dictionary of Measures to Produce Reliable Software The Software Productivity Consortium, Ada Quality and Style Guidelines for Professional Programmers ANSI/IEEE Std 1063-1987, IEEE Standard for Software User Documentation

\subsection{References}

NIF-LLNL-93-044/L-15958-1, National Ignition Facility Quality Assurance Program Plan, November 1993 NIF-LLNL-94-017/L-15958-5, NIF Ancillary Software Quality Assurance Plan, January 12, 1994 NIF-LLNL-93058, National Ignition Facility Functional Requirements and Primary Criteria

\subsection{Requirements and Verification}

\subsection{System Definition}

The Target Diagnostic Subsystem (WBS 1.8.3) shall provide the optical, $x$-ray and nuclear diagnostics required for laser system performance and verification test. The facility shall also provide support for the diagnostics for radiation effects testing, and other applications and experiments as needed.

The Target Diagnostic Subsystem's initial function is to verify laser system performance on target. The verification of laser system performance on target is specified in the "Startup Experimental Plan", Document L16973-1, pages 3-74, 5-385. The major functions necessary to verify laser system performance on target are:

- Measure the simultaneity of arrival of pulses from individual beamlines.

- Measure the laser beam positioning accuracy.

- Measure the laser spot size.

- Measure laser pulse smoothness.

In addition, the target diagnostic subsystem shall also provide for eventual diagnosis of ignition and weapons physics experiments, making the following measurements possible: $\bullet$ Measure symmetry of $\mathrm{x}$-ray emission from imploded cores.

- Measure the motion of the X-ray emitting volumes in hohlraums.

- Measure the radiation flux out of hohlraums within the photon energy range $0.15-2.5 \mathrm{keV}$.

- Measure the strength of radiation driven shocks.

- Measure fusion yield.

- Measure the symmetry of neutron emission from imploded cores.

- Measure the ion temperature of the compressed fusion fuel.

- Measure the duration and time of the thermonuclear burn.

- Measure the number and energy distribution of fast electrons in hohlraums.

- Measure the radiation flux out of hohlraums.

- Measure the laser light backscatter from the target.

\subsubsection{System Description}

The Diagnostic Subsystem described in this SSDR includes the various diagnostic equipment and the front end processors that support each of the diagnostcs. The diagnostic equipment described include:

Diagnostic Instrument Manipulator (DIM): The Diagnostic Instrument Manipulator is a diagnostic platform used to insert and retract a variety of instruments into the target chamber. The DIM will provide a standard set of utilities to support the operation of instruments that require insertion into the target chamber. The DIM will be designed to fit on any of the diagnostic ports on the target chamber. The DIM will provide precision radial positioning, pointing, and alignment capability. 
Time Resolved X-Ray Imaging System (TRXIS): A Time Resolved X-Ray Imaging System is part of the NIF laser system performance and verification on target diagnostics set. This instrument will produce time resolved $x-$ ray images of target emissions of energies above $1 \mathrm{kev}$. The diagnostic will have sufficient spatial resolution, temporal resolution and field of view to diagnose the performance of the laser on low to medium power disk

shots. Performance parameters to be measured will include laser spot size, spot location and beam smoothing.

X-Ray Streak Slit Camera (XSSC): A X-Ray Streak Slit Camera will be part of the laser system performance and verification on target diagnostics set. This diagnostic will be designed to produce time resolved streak images of target emission in the energy range between 0.1 and $10 \mathrm{keV}$, with sufficient spatial resolution, temporal resolution, and field of view to diagnose the laser beams synchronization at the target. This diagnostic will also be used to measure beam smoothing, $x$-ray pulse wave shape, and beam spot movement.

Static X-Ray Imaging System (SXD: The Static X-Ray Imaging System will be deployed as part of the laser system perofmance and verification diagnostic set. The SXI will produce time integrated images of $\mathrm{x}$-ray emmisions in the energy range between $2-3 \mathrm{keV}$, with sufficient spatial resolution and field of view to diagnose beam pointing and spot size. The SXI will monitor the beam pointing on all hohlraum target shots. Beams that miss the laser entrance hole will produce an X-ray emission on the outside of the hohlraum, indicating improper alignment of the laser. There will be two SXI systems. Each will view one end of the hohraum. The SXI will also be used to determine beam poinitng accuracy on target by producing a time integrated image of the $\mathrm{x}$-ray emmision produced by a subset of laser beams irradiating a test target.

\subsubsection{Target Diagnostic Data Acquisition System}

The Target DAS is an extension of the ICCS. The Target DAS shall be designed to be software and hardware compatible with the ICCS. Refer to the ICCS Computer System SSDR and the Supervisory Control Software SSDR. These SSDR's define the computer system up to and including part of the Front End Processors (FEPs). This SSDR defines the Target Data Acquistion System from the FEPs to the diagnostic equipment. Hardware components that are the same or compatible with those components in the ICCS shall be used in the design and development of the Target DAS. The software development tools used to develop the software for the Target DAS shall be compatible with the software development tools used to develop the software for the Supervisory Computer System.

\subsubsection{System Functions}

The Target Diagnostic Subsystem (WBS 1.8.3) shall provide the $\mathrm{x}$-ray diagnostics required for laser system performance and verification tests on target. In addition, accommodations shall be made to support diagnostics , and for ignition and weapons physics experiments. The Target Diagnostic Subsystem shall also accommodatethe required diagnostics for radiation effects testing, and other applications and experiments as needed.

\subsubsection{System Diagrams}

\subsubsection{System Operating Modes}

Figure 3.1.3.1-1 identifies the sequence of operating modes planned for the NIF facility. The Target

Experimental System will also operate in all these modes, following the same scenario as the overall facility 


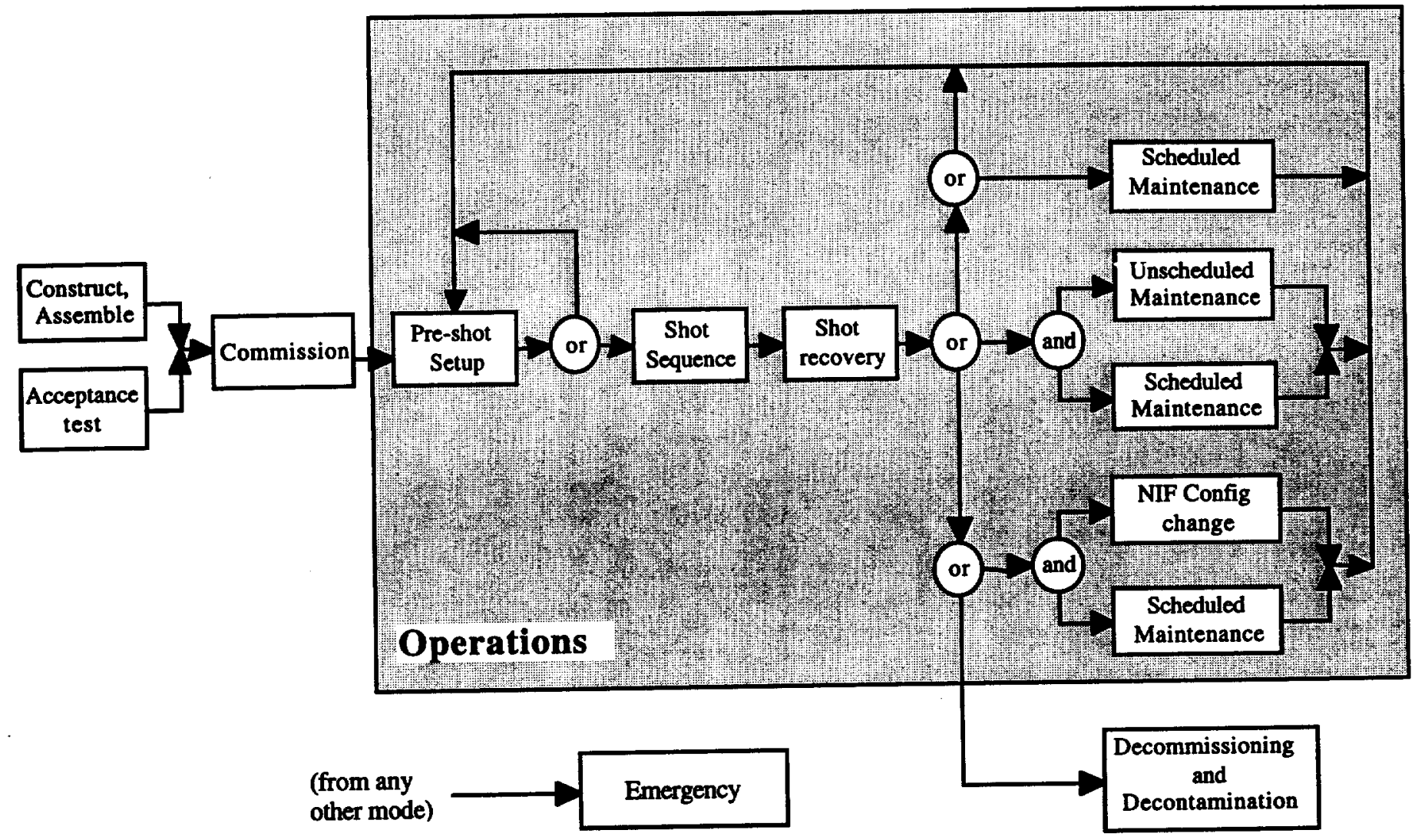

Figure 3.1.3.1-1 NIF operating modes

\subsubsection{Dry Run Operating Modes}

The Target Diagnostic Systems will operate in either of two basic modes. The first is the dry run operating mode. This operating mode is designed to check the operation of the diagnostics without firing the laser system. The second mode is the data acquisition operating mode. This is the mode where the laser system is fired and real data is collected. The figure below is a flow diagram of these two modes. The principal difference is as noted above. For the Dry Run Mode, some stimulus is triggered at to to simulate the laser firing. This stimulus is designed so as to test as much of the diagnostic system as possible. All diagnostic systems shall be designed to incorporate a dry run operational mode. 


\section{Diagnostic Data Acquisition and Dry Run Data Flow Chart}

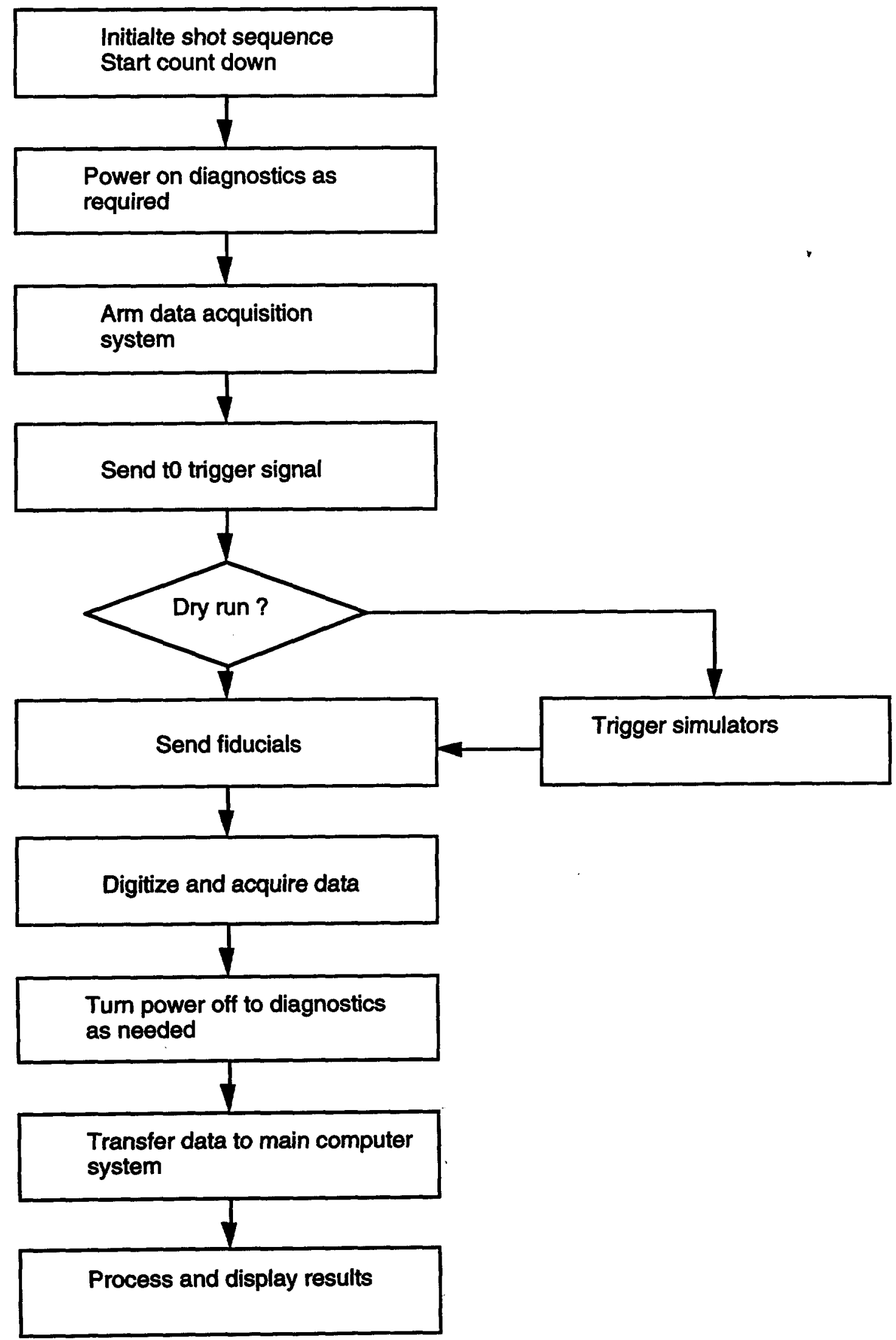




\subsubsection{System Interfaces}

The Target Area Diagnostic System has major interfaces with the following systems:

The Target Chamber (WBS 1.8.1)

As regard to attachment, geometry, vacuum isolation, vibration isolation, and first wall protection.

The Diagnostic Vacuum System (WBS 1.8.3.7)

Several of the diagnostics require vacuum for proper operation.

The Integrated Timing System (WBS 1.5.3)

The diagnostics require precision timing and fiducial signals that are synchronized with the operation of the laser for accurate analysis of data. The Target Area Timing/Trigger and Fiducial System shall be an integral part of the facility Integrated Timing System.

The Integrated Computer Control System (WBS 1.5)

The target area diagnostic system requires remote and local control and monitoring. Also, performance data on the laser will be required for archiving along with experimental data for accurate data analysis.

The Target Area Structures (WBS 1.8.4)

The diagnostics require sufficient foundation stability to meet requirements pointing and vibration specifications. There are several diagnostics that require openings in walls and floors.

The Integrated Safety System (WBS 1.5.4.1)

The Target Area Personnel Safety System shall be an integral part of the facility safety system.

The Environmental Protection System (WBS 1.8.5.4)

The handling of chamber mounted, and reentrant diagnostics will require that these procedures be compatible with those specified in the Environmental Protection System SSDR.

3.1.5 Major Subsystems The major subsystems of the Target Area Diagnostic System are:

Laser system performance and verification diagnostics

Diagnostic Instrument Manipulator (DIM)

Time Resolved X-Ray Imaging System (TRXI)

X-Ray Streak Slit Camera (XSSC)

Static X-Ray Imaging System (SXI)

Data Acquisition System

Target Area Timing/Trigger and Fiducial System

Diagnostic Vacuum System

EMI Protection, Grounding and Shielding, and Radiation Susceptibility

Unclassified Control Room

Classified Control Room

\subsection{System Characteristics and Verification}

The following sections define the minimum requirements which must be met by the Target Diagnostic Subsystem, related to performance, physical characteristics, etc. The approach for verifying that the design and the hardware meets each requirement is listed for each.

\subsubsection{Laser system performance and verification diagnostics}

To verify laser system performance, the following measurements shall be made:

Measure the simultaneity of arrival of pulses from individual beamlines.

Measure the laser beam positioning accuracy.

Measure the laser spot size. 
Measure laser pulse smoothness.

The diagnostics selected to make the required laser system performance and verification measurements are:

Time Resolved X-Ray Imaging System (TRXI)

X-Ray Streak Slit Camera (XSSC)

Static X-Ray Imaging System (SXI)

The details for these diagnostics are contained in the ICD for that diagnostic.

\subsubsection{Ignition and Weapons Physics Experimental Diagnostics}

The diagnostic subsystem shall provide accommodations for the eventual diagnosis of the Ignition and Weapons

Physics Experiments, making the following measurements possible:

Measure symmetry of $x$-ray emission from imploded cores.

Measure the motion of the $x$-ray emitting volumes in hohlraums.

Measure the radiation flux out of hohlraums within the photon energy range $0.15-2.5 \mathrm{keV}$.

Measure the strength of radiation driven shocks.

Measure fusion yield.

Measure the symmetry of neutron emission from imploded cores.

Measure the ion temperature of the compressed fusion fuel.

Measure the duration and time of the thermonuclear burn.

Measure the number and energy distribution of fast electrons in hohlraums.

Measure the radiation flux out of hohlraums.

Measure the laser light backscatter from the target.

The following list contains those systems identified to make the above required measurements for Ignition and Weapons Physics Experiments:

Soft X-Ray Imaging System (SXRI)

Soft X-Ray Power Diagnostic System (SXPD)

Passive Shock Break-out Diagnostic System (PSBO)

Active Shock Break-Out Diagnostic System (ASBO)

Filter Fluorescer Diagnostic System (FFLEX)

Total Neutron Yield Diagnostic System (NY)

Neutron Time-of-flight Diagnostic System (NTOF)

Neutron Imaging System Diagnostic System (NI)

Neutron Spectrometer Diagnostic System (NS)

Bang-time and Burn Duration Diagnostic System (BTBD)

Neutron Coded Aperture Microscope Diagnostic System (NCAM)

Gamma Ray Spectrometer Diagnostic System (GRS)

Full Beam Laser Backscatter System (FBLB)

The details for these diagnostics are contained in the ICD for that diagnostic. Ports on the target chamber, and stayout zones shall be designed into the NIF so as to not preclude the addition of these diagnostics later. The DAS shall also be designed to easily accomodate the addition of these diagnostics and required operating modes.

\subsubsection{Diagnostic Instrument Manipulator (DIM)}

\subsubsection{Performance Characterisites}

Shall provide the capability to place a diagnostic package to any position radially between the target chamber wall and the target chamber center to an accuracy of 0.25 millimeters. Repeatability of placement shall be better than 0.25 millimeters .

Shall provide pointing accuracy's of \pm 25 microns displacement in $x$ \& y directions at target chamber center. Repeatability of pointing positioning shall be better than \pm 25 microns.

Shall provide angular pointing capability of \pm 3 degrees at the point of mounting at the chamber wall. 
Shall be capable of placing the diagnostic carts into the DIM while the target chamber is under vacuum.

The diagnostic carts shall be loadable into the exterior DIM tube from the side or top near the end of the DIM that is away from the target chamber,.

Shall be capable of operation in any port from horizontal to vertical (up or down).

Shall have a diagnostic cart load and unload time less than 10 minutes.

The part of the DIM which is inserted into the target chamber must be removable from the interior of the chamber within 15 minutes.

The DIM components shall be removable from the target chamber by 2 people in 2 hours.

The diagnostic carts shall remain stationary upon loss of power with the DIM in any position on the target chamber.

The DIM shall be backward compatible with Nova SIM diagnostic carts and LLE 10 inch diagnostic carts.

\subsubsection{Physical characteristics}

\subsection{General (size, configuration, etc.)}

Shall be compatible with the $45.7 \mathrm{~cm}$ diameter port on the target chamber.

Shall be able to accommodate carts of $300 \mathrm{~mm}$ (11.8") in diameter centered on the axis of the tube and $3000 \mathrm{~mm}$ (118.1") in length.

The length of the portion of the DIM exterior to the target chamber shall permit at least a 2 meter pathway around the outside edge of the target bay. The maximum length is 7.7 meters.

The portion of the tube outside the target chamber must have glass viewports for observing the carts inside while under vacuum.

Shall maintain a smooth surface on the inserted part of the DIM to minimize contamination.

Shall minimize any openings between inserted portions of the DIM and the outer portions to minimize contamination of outer portion of the DMM.

Shall be constructed to conform to the material and size standards used for the other target area mechanical components.

Each cart shall incorporate a flexible, traveling utility bundle that includes signal cables, high bandwidth coaxial cables, power cables, fiber optic cables, and gas tubing.

Shall provide connections to the roughing vacuum system, 10-1 torr.

Shall be compatible with a working pressure of $5 \times 10-5$ to $1 \times 10-6$ torr.

Shall be designed so that the central $100 \mathrm{~mm}$ portion of the tube is unobstructed when the diagnostic package is not installed. 


\subsection{Material (contamination, vacuum, activation)}

Shall incorporate materials that are compatible with and do not contaminate the chamber vacuum system.

Shall avoid the use of plastics where possible.

Any necessary plastic materials that could be exposed to chamber laser light must be protected by another layer such as metal.

Any wiring that could be exposed to chamber light must be enclosed in a full metal jacket such as flexible tubing with venting holes; stainless steel braiding will only be acceptable if coverage is $>98 \%$.

The support tube shall consist of materials that are compatible with NIF activation requirements.

\subsection{Electrical (wiring, shielding, fiber optics, controls, etc.)}

Shall include absolute encoders to provide location of each cart along the tube to an accuracy of $0.1 \mathrm{~mm}$.

The drive system shall consist of motor drives compatible with other NIF components.

Signal cables connected to each cart shall consist of 10 twisted pair, 18 gauge conductors.

High bandwidth coaxial cables shall consist of 4 cables with attenuation specifications better than $22.5 \mathrm{db} / 100 \mathrm{ft}$ at a frequency of $10 \mathrm{Ghz}$.

Power cables connected to each cart shall consist of 6 twisted pair, 16 gauge conductors.

Fiber optic cables connected to each cart shall consist of 4 multimode fibers.

\subsection{Mechanical (stability, deflection, load)}

The DIM carts must be stable to less than TBD mm RMS as a result of TBD $\mathrm{g} 2 / \mathrm{Hz}$ input vibration at the special equipment support location.

The static deflection of cart must be less than $0.76 \mathrm{~mm}\left(0.030^{\prime \prime}\right)$.

Gas lines connected to each cart shall consist of two $0.635 \mathrm{~cm}\left(1 / 4^{\prime \prime}\right)$ diameter tubes.

Shall be capable of positioning the diagnostic package at any radial position from the chamber wall to TCC. .

Shall support a maximum diagnostic package mass of $195 \mathrm{~kg}(430 \mathrm{lbs})$, center of mass located a maximum of 2.5 meters from chamber wall.

Shall accommodate a diagnostic package of less than or equal to 3 meters.

\subsubsection{Target Area Data Acquisition System}

\subsubsection{Unclassified Data Acquisition System}

\subsection{Performance Characteristics}

The Target DAS will record signals from diagnostic devices associated with NIF target chamber experiment shots. The Target DAS will also control the diagnostic hardware.

There are two potential types of NIF Target diagnostics. The first type are data recorders which require control commands and which record and output data over a computer interface bus. Some of these devices will be sophisticated single-purpose diagnostics that will mount directly on the target chamber. Others are general purpose recorders such as waveform recorders that will be housed in DAS shielded enclosures. The second type 
are ancillary support devices such as bias supplies, pulse generators, switches, etc. These devices only require control commands. Although devices of the second type do not return data, they may return setting and status information. Target diagnostic hardware of both types will be referred to as "diagnostic devices" in the rest of this document.

The Target DAS receives command messages from the NIF Integrated Computer Control System (ICCS) Supervisory software and converts these messages into control commands for the various diagnostic devices. When the Target DAS software receives a Read-Data message, it will read data from the selected diagnostic and send this data to the Supervisory level

The Target DAS will use computer controlled data recorders and produce digitized output data. As such it will incorporate a computer network and software for instrument control and data reduction. Overall requirements for these items are also included below.

Not all of the above diagnostic devices will be used in the first stage of the NIF operations. However since all of them will be used in some stage, the requirements will be addressed for all of them. The Target DAS will be designed using the "Do Not Preclude" (DNP) principle.

Many of these diagnostic devices are imaging type that produce a two-dimensional image of the data recorded on an internal CCD camera. Much of the Target DAS will be dedicated to reading out these images and retransmitting the data to the archive at the ICCS Supervisory level. Also many of these devices will produce analog waveforms either as the direct quantity being measured or as internal health monitoring signals.

An overall description of the performance of these diagnostics from the standpoint of their function as a NIF Target diagnostic is given in Section 3.1.1.1 of this SSDR. The specific control, data readout, auxiliary recording requirements for each of the custom devices are given below.

A major part of the NIF Target DAS will be an analog recording system for recording signals directly from NIF diagnostics that produce analog output signals. The analog recording system will also be used to record signals from the custom diagnostics described in Section 3.1.1.1 that require recording of state-of-health analog signals. The performance requirements for the analog recording system are given below.

The performance specifications given are for the entire recording system. System amplitude and timing accuracy's, bandwidth, and dynamic range are affected by all of the items below:

-cable system

- EMP and radiation shielding

- grounding philosophy

- signal conditioning components

- waveform recorders

- trigger and time alignment subsystem

- internal/external calibration subsystem

-software signal processing possibly including system frequency response equalization and noise reduction filtering

Note that if either hardware or software cable frequency response compensation is required to meet a given bandwidth, then the compensated signal must meet all performance specifications.

The analog recording system will be broken into a number of different frequency bands. The breakup will be dictated by the technology used in the cable plant and in the waveform recorders for a specific band. We currently anticipate three bands:

High Frequency - this band will be used for very fast signals that approximate the temporal nature of the NIF laser pulse and the target physics interactions. 
Mid Frequency - this band will be used mainly for custom diagnostic housekeeping functions such as monitoring pulsed bias signals.

Low Frequency - this band would be primarily used both for low frequency housekeeping signals and for thermomechanical weapons effects experiments.

The mode of calibration for a given frequency band shall be selected to meet the accuracy requirements for the signals being recorded in each band and taking into account the inherent accuracies of the system hardware especially the waveform recorders.

The Target DAS will provide users with data waveforms that are aligned in time both relatively to each other and absolutely to some well-defined NIF event, e.g., the $50 \%$ point of the laser pulse output.

\subsection{Computer/Software System Performance Requirements}

The computer system and software shall be designed to maximize efficiency of operation, meet the required data throughput times, provide for required on-line data storage and data transfer capabilities, and interface with other NIF facility subsystems. The computer system and software must provide for future expansion without sacrificing either efficient operation or throughput time performance. The specifications on computer system performance apply to the combination of the ICCS computers at the Supervisory level and the Front End Processors (FEP) used at the Target DAS level.

\subsection{Efficiency of Operation}

Efficiency of operation is determined primarily by the capabilities of the applications software and the computer operating software. The requirements for the Supervisory level computing systems are covered in detail in the NIF ICCS SSDR.

\subsection{Throughput Time Requirements}

The throughput time requirements for the various operations associated with automated data acquisition are: Instrumentation Database Setup

- Setup time for a complex experiment with minimal similarity to a previous test should be less than 2 hours.

- Setup times for the instrumentation database will vary greatly depending on the complexity of an experiment and the similarity to any previous experiment.

Auto test/auto calibration to be accomplished in $<1$ hour

Send programmable settings to recording equipment $-<15$ minutes

Preshot Test and/or autocalibration $-<15$ minutes

Arm for Shot - $<5$ TBD minutes

Read and archive Raw Data - $<15$ minutes after shot

Provide quick look capability of acquired data.

"Quick look data" is Raw digitizer data, possibly in counts, converted either to volts output from the gage or possibly a scalar multiplicative conversion of volts to engineering units into the gage. It does include possible application of a software frequency response compensation filter.

\subsection{Data Storage and Transfer Requirements}

The Supervisory level ICCS computer system associated with the Target DAS shall have on-line storage for at least 1 week of shots using all recording channels and memory. The Target DAS shall provide data to users in the following formats as specified in the Supervisory DAS SRS document.

\subsection{Terms and Test Methods}

The terms Full Scale Range, Signal-to-Noise Ratio, Step Response Overshoot, are well-defined in IEEE Std. 1057 Standard for Digitizing Waveform Recorders. Although the document was written explicitly for testing Waveform Recorders, many terms and test methods are applicable to the full recording system. 
A repeatable, objective method should be used for measuring Gain Accuracy. A suggested method is to use the histogram method described in IEEE Std. 181-1977 IEEE Standard on Pulse Measurement and Analysis by Objective Techniques. The histogram technique should be used to measure the height of a known amplitude, flattop, rectangular pulse whose pulse width is in the 100 to 200 sample range.

\subsubsection{Classified Data Acquisition System}

\subsection{Performance Characteristics}

The Classified Target Area Diagnostic Data Acquisition System shall comply with the same performance characteristics as the Unclassified Data Acquisition Systems as defined in section 3.2.3.1. Additional performance requirements include the following. The Classified DAS shall conform to the NIF Classification Guidline, to all LLNL Computer Classification Guides, and to all DOE Orders defining the collection and handling of 'SRD' information.

\subsubsection{Other Diagnostic Systems}

This system also includes the front end processors that control and acquire data from the various diagnostics, the unclassified and classified data acquisition and analysis computer systems, the timing/trigger and fiducial system, the target area control system, and various other systems. The Figure 1 shows a typical arrangement of diagnostic components, front end processors, and computer systems. Figure 2 shows the position of the various diagnostics on the target chamber.

\subsubsection{Target Area Timing/Trigger and Fiducial System}

There shall be a timing/trigger and fiducial system to provide support to the various diagnostics and data acquisition systems in the Target Experimental Area. This system shall be an integral part of the facility Integrated Timing System. Refer to the Integrated Timing System SSDR4-WBS1.5.3 for detailed information. Only design requirements not covered in the ITS SSDR will be included below.. Design requirements shall include the following.

\subsubsection{Fast Timing Signals}

These timing signals shall be used to signal FEPs and other control equipment different events during the shot countdown. It will arm various data acquisition storage equipment to get ready to record data from such equipment as transient digitizers, and imaging cameras.

\subsection{Performance Characteristics}

The timing system shall provide electrical signals as specified in the ITS SSDR.

3.2.05.1.2 Physical Characteristics Fast timing signals shall be available at multiple locations around the Target Experimental Area. This includes 4 locations at diagnostic racks located on mezzanines in both switchyards, in the classified data acquisition room, in the unclassified control room, and in the local unclassified and classified data acquisition areas.

\subsubsection{Precision Timing Signals}

These signals shall be used to trigger transient digitizers, pulsers, and sweep generators. Errors such as jitter shall be minimized.

\subsection{Performance Characteristics}

Shall provide electrical and optical trigger signals.

Electrical triggers shall have:

amplitude of $\sim 10$ volt.

100 psec risetime at source.

programmable delay resolution of 5 psec.

programmable delay range of $1 \mathrm{msec}$. 
synchronized with the MOR laser pulse with a RMS jitter of $<50 \mathrm{psec}$.

Optical triggers shall have:

$100 \mathrm{psec}$ risetime at source.

programmable delay resolution of $5 \mathrm{psec}$.

programmable delay range of $1 \mathrm{msec}$.

synchronized with the MOR laser pulse with a RMS jitter of <50psec.

\subsection{Physical Characteristics}

All types of the timing and trigger signals shall be available at multiple location around the target area. This includes 4 locations at diagnostic racks located on mezzanine in both switchyards, in the classified data acquisition room, in the unclassified control room, and in the local unclassified and classified data acquisition areas.

\subsubsection{Fiducal Optical and Electrical Signals}

The fiducials, both optical and electrical, are used to accurately mark monitors and data from the various diagnostics so that the data sets can be synchronized. Errors such as jitter will need to be minimized.

\subsection{Performance Characteristics}

Shall provide electrical fiducial signals, synchronized with MOR laser with a RMS jitter of $<$ TBDpsec, pulse width of 200psec, amplitude 10volts.

Shall provide optical fiducial pulses, synchronized with MOR laser with a RMS jitter of $<\mathrm{TBDpsec}, 200 \mathrm{psec}$ wide.

Shall provide a series of optical timing marker pulses, $200 \mathrm{psec}$ wide, 1 pulse/nsec, for $30 \mathrm{nsec}$.

Shall measure the time difference between any one of the trigger signals and the optical fiducial to $<5$ psec.

\subsection{Physical Characteristics}

All types of signals available at multiple location around the target area. This includes 4 locations at diagnostic racks located on mezzanine in both switchyards, in the classified data acquisition room, in the unclassified control room, and in the local unclassified and classified data acquisition areas.

\subsubsection{Diagnostic Vacuum System}

There shall be a diagnostic vacuum system which shall provide centrally located and readily accessible vacuum system for support of the various diagnostics distributed around the target area. This vacuum system shall be considered as part of the Target Chamber Vacuum System. Design requirements shall include:

\subsubsection{Performance Characteristics}

Shall provide rough vacuum - around $5 \times 10-1$ torr.

Shall provide high vacuum - between $5 \times 10-5$ and 1 X 10-6 torr.

Shall provide an exhaust system to provide negative pressure to help contain contamination when opening the vacuum vessels around the diagnostic equipment.

Shall provide each of the above at each diagnostic position.

\subsubsection{Physical Characteristics}

The output side of all vacuum pumps shall be connected to the Tritium Processing System when necessary.

Vacuum support shall be available at all diagnostic locations on and around the target chamber. 


\subsubsection{EMI Protection, Grounding and Shielding, and Radiation Susceptability} The design of the Target Experimental System shall conform to the "NIF Grounding and Shielding Plan". Conformance to this plan will mitigate the magnitude of the EMI/EMP interference throughout the Target Experimental and Switchyard areas.

Ionizing radiation effects on equipment are an issue inside the Target Bay building. Carefull consideration shall be given to the design of all systems that reside inside the Target Bay shield wall.

The radiation and EMI levels and effects are described in the report UCRL-ID-118202, "Radiation and EMI Effects in the NIF Environment".

EMI and radiation shielding shall be required for sensitive equipment in all areas of the Target Experimental Area.

\subsubsection{Unclassified Control Room}

\subsubsection{Performance Characteristics}

There shall be area set aside in the main Control Room for a console to control and monitor the diagnostics equipment and the other target area systems.

There shall be resources available to do quick look type of data processing of unclassified experimental data.

There shall be an area set aside in the Target Diagnostic Building to be used for a diagnostic control room. This local control room will have the same functionality as the main control room. The local control room shall be used for setup, checkout, and maintenance functions. During shots, all functions shall be transferred to the main control room.

There shall be an area set aside in the Target Diagnostic Building to be used for a local unclassified data acquisition room. This local unclassified data acquisition room will have the same functionality as the main control room for monitoring and acquiring data from the various diagnostics. The local unclassified data acquisition room shall be used for setup, checkout, and maintenance functions. During shots, all functions shall be transferred to the main control room.

Users which bring their own data acquisition and control systems shall use the local areas located in the Diagnostic Building for the support of their unclassified experimental diagnostic systems.

3.2.08.2 Physical Characteristics The main unclassified control room is defined in SDR004-ICCS-Computer System-WBS1.5.1.

The local unclassified control room shall be located in the Diagnostic Building.

The local classified data acquisition room shall be located in the Diagnostic Building.

\subsubsection{Classified Control Room}

For classified experiments, some or all of the data from the diagnostics shall be classified. For those diagnostics that are part of the facility and/or mounted in the DIMs, they shall be controlled and monitored by the classified data acquisition system which resides in the classified control room. For those data acquisition systems brought in by various users for specific classified experiments, a local classified control room shall be provided. The classified control room shall be designed to conform with the method of operations as defined in the NIF classification guidelines 


\subsubsection{Performance Characteristics}

Shall conform to the NIF Classification Document and all applicable DOE guidelines for 'SRD' level of classification.

\subsubsection{Physical Characteristics}

The classified control room is in the main LTAB building next to the main control room.

\subsubsection{Reliability, Availability, Maintainability}

\subsubsection{Lifetime}

The Target Area Diagnostic System shall have a lifetime of 30 years.

\subsubsection{Replaceability}

Any portion of the Target Area Diagnostic System which cannot be reasonably designed for a 30 year lifetime shall be designed to be replaced or repaired at resonable cost in a timely manner consisten with the overall availability of the system and annual maintainance budget allocations.

\subsubsection{Inherent Availability}

The target area diagnostics subsystem shall have a shot availability of at least $99.79 \%$. The system is unavailable when it is undergoing unplanned maintenance. Unplanned maintenance includes failure detection and active repair as well as logistic and administrative downtimes. The parts of the system not required to support a shot can be undergoing repair and maintenance without affecting the subsystem's unavailability.

At least TBD \% of the advertised number of data recording channels in each bandwidth range shall be available to experimenters on each NIF shot. The facility shall meet this specification via some combination of spare units and readily available maintenance arrangements. Instrument cooling will also strongly affect system reliability.

\subsubsection{Reliability}

All diagnostics shall be designed with the capability to perform 'dry run' exercises. These dry run exercises will consist of the same timing and trigger steps for a regular system shot, except that the laser is not required to fire. Each diagnostic will be designed with a method to inject data into the front end of the diagnostic to maximize the extent of the system that can be verified.

On a given NIF shot at least $99.01 \%$ of the channels being used in each bandwidth range shall meet the recording system performance specifications outline above in sections 3.1 thru 3.3. This requirement shall not apply in the case of offscale or extremely low recorded signal levels due to improper experimenter predictions.

No single point failure of any system component shall prevent the Target DAS from collecting data on a shot. In addition no dual simultaneous failure of a computer system CPU and disk drive shall prevent the Target DAS from collecting data. The data throughput specifications given in section 3.2 shall be degraded by no more than a factor of TBD when collecting data in a backup mode due to a subsystem failure.

The facility shall provide for on-site maintenance of computer system hardware with a 4 hour maximum response time.

The quality of the Target DAS shielded enclosure air conditioning system will greatly impact system reliability.

\subsubsection{Maintainability}

The target area diagnostics subsystem shall have a scheduled maintenance plan that fits within an overall annual plant goal of 69 days. The unplanned maintenance goal is 13 hours per year. Opportunistic maintenance activities are performed between shots and during other system downtimes. 


\subsubsection{Recovery from Abnormal Events}

The time required for the target area diagnostics subsystem to recover from any abnormal event shall be less than the maximum times cited below, as a function of the expected yearly frequency of occurrence of the event.

$\begin{array}{rc}\text { Expected Frequency of Occurrence Per Year, } F & \text { Maximum Recovery Time } \\ F \geq 1 & 24 \text { hours } \\ 1>F>1 e-2 & 1 \text { week } \\ 1 \mathrm{e}-2>\mathrm{F} \geq 5 \mathrm{e}-4 & 3 \text { months }\end{array}$

Probabilities listed in DOE-STD-1020-94 shall be used for natural phenomena.

For frequent events, the maximum allowed recovery time may be restricted by availability requirements to be less than that shown in the table above.

\subsubsection{Environmental}

The site for NIF has not yet been selected. The present design is therefore non-site-specific. For the purpose of Title I design of the Target Experimental System, it shall be assumed that NIF will be constructed at a site with the general infrastructure as available at candidate sites. Specific environmental assumptions are listed in the following sections

\subsubsection{Ambient Temperature, Humidity, and Pressure}

The Target Area Diagnostic System components shall be design to reliably operate in the environment in which the component resides.

\subsubsection{Vibration Enviroment \\ T B D}

\subsubsection{EMI, EMP, and Radiation}

The Target Area Diagnostic System components shall be designed to reliable operate in the electrical and radiation environment in which the component resides. The design of each system shall be reviewed with the environmental conditions as one of the requirements.

\subsection{Design and Construction}

\subsection{Logistics}

\subsubsection{Spares}

As a part of the design/construction project, the Integrated Timing System shall provide an initial compliment of spare parts as required to activate the system.

\subsubsection{Maintenance}

As a part of the design/construction project, the Integrated Timing System shall provide all equipment required to inspect, service, and maintain all subsystems within the Integrated Timing System to meet the maintainability and availability requirements. Maintenance equipment shall include all handling fixtures, lifting equipment, and other special tools not otherwise available within the NIF, that are necessary to perform any planned (scheduled or unscheduled) maintenance activity.

\subsection{QA Provisions}

Quality Assurance for this subsystem will be determined by verification methods identified in $\$ 3$, in combination with the identified Quality Level for individual components. 


\subsection{Q-level Assigned}

\begin{tabular}{|c|c|c|c|c|c|}
\hline \multirow[t]{2}{*}{$\begin{array}{l}\text { WBS } \\
\text { element } \\
\text { number }\end{array}$} & \multirow[t]{2}{*}{ WBS element title } & \multicolumn{3}{|c|}{$\begin{array}{l}\text { Assigned } \\
\text { Q-level }\end{array}$} & \multirow[t]{2}{*}{ Why not Q-level 3 ? } \\
\hline & & 1 & 2 & 3 & \\
\hline 1.8.3.1.1 & $\begin{array}{l}\text { Time Resolved X-Ray Imaging } \\
\text { System (TRXI) }\end{array}$ & & & $\sqrt{ }$ & \\
\hline 1.8 .3 .1 .2 & X-Ray Streaked Slit Camera (XSSC) & & & $\sqrt{ }$ & \\
\hline 1.8 .3 .1 .3 & Static X-Ray Imaging System (SXI) & & & $\sqrt{ }$ & \\
\hline 1.8 .3 .2 & Diagnostic Instrument Manipulator & & & $\sqrt{ }$ & $\begin{array}{l}\text { administrative controls will be } \\
\text { developed (conventional safety } \\
\text { procedures) }\end{array}$ \\
\hline 1.8 .3 .3 & $\begin{array}{l}\text { Target Area Data Acquisition } \\
\text { System }\end{array}$ & & & $\sqrt{ }$ & \\
\hline$\overline{1.8 .3 .4}$ & $\begin{array}{l}\text { Target Area Integrated Command } \\
\text { and Control System }\end{array}$ & & & $\sqrt{ }$ & \\
\hline 1.8 .3 .5 & Timing and Fiducial Systems & & & $\sqrt{2}$ & \\
\hline 1.8 .3 .6 & EMI / EMP and Radiation Protection & & & $\sqrt{ }$ & \\
\hline 1.8 .3 .7 & Diagnostic Vacuum System & & & $\sqrt{ }$ & \\
\hline
\end{tabular}

\subsection{Revision Record}

\begin{tabular}{|l|l|l|l|l|}
\hline Rev & Date & ECR\# & B y & Description of/Reason for Change \\
\hline 0 & CDR & n/a & & \\
\hline A & $6 / 4 / 96$ & $n / a$ & Lee & inital Title I issue \\
\hline B & $10 / 28$ & 73 & Lee & final Title I update, many miscellaneous changes, TBDs removed \\
\hline
\end{tabular}




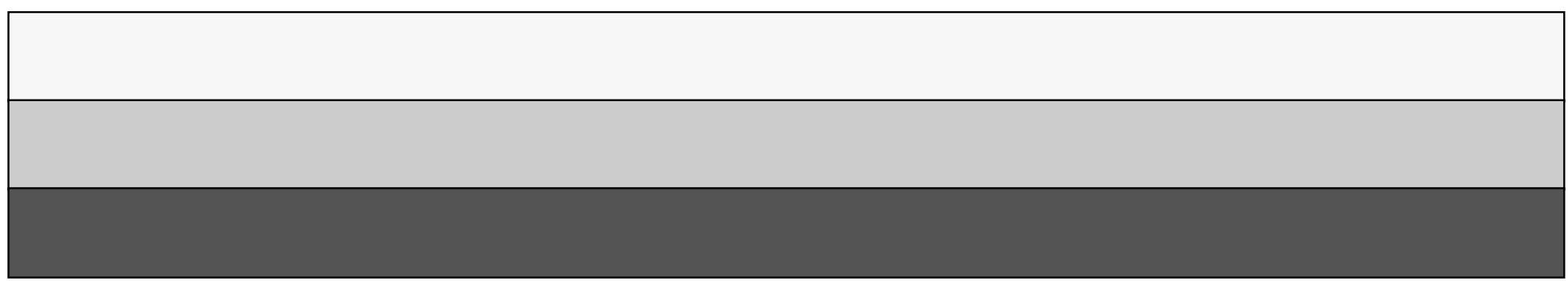

